\title{
Trabalho e saúde do trabalhador no contexto atual: ensinamentos da Enquete Europeia sobre Condições de Trabalho
}

\author{
Work and worker's health in the current context: what the \\ European Working Conditions Survey teaches us
}

Ana Claudia Cardoso ${ }^{a}$

(iD) https://orcid.org/0000-0003-3279-9411

E-mail: anacmc2ळhotmail.com

\section{Luciana Morgado ${ }^{b}$}

(D) https://orcid.org/0000-0003-1061-1983

E-mail: lucianalpm24@gmail.com

a Universidade Federal de Juiz de Fora. Instituto de Ciências Humanas. Departamento de Pós-Gradução. Juiz de Fora, MG, Brasil.

bUniversidade de São Paulo. Faculdade de Saúde Pública. São Paulo, SP, Brasil.

\section{Correspondência}

Luciana Morgado

Av. Doutor Arnaldo, 715, Pinheiros. São Paulo, SP, Brasil.

CEP $01255^{-000}$

\section{Resumo}

Este artigo visa contribuir para as reflexões sobre a construção de uma pesquisa nacional, no Brasil, que aborde a relação entre trabalho e saúde dos trabalhadores. Uma pesquisa que produza conhecimentos para subsidiar as ações dos atores sociais nos seus diferentes espaços, como o da negociação coletiva e da construção de políticas públicas, e sobre os determinantes do processo saúde-doença, dado que, se a sociedade tiver como objetivo resolver o problema do sofrimento, do adoecimento e dos acidentes vinculados ao trabalho, não será possível manter o foco apenas nas consequências desses eventos, sendo necessário também atuar sobre suas causas. Para realizar tal reflexão, será utilizado a European Working Conditions Survey (EWCS), aplicada nos países da União Europeia (UE) desde 1990, que traz informações sobre como as diferentes dimensões do trabalho vêm impactando a saúde dos trabalhadores, servindo como importante referência para a elaboração de políticas públicas objetivando melhoria das condições de vida e trabalho dos trabalhadores europeus.

Palavras-chave: Saúde do Trabalhador; Pesquisa de Saúde; Risco Psicossocial. 


\section{Introdução}

This article is a contribution to the ongoing discussion concerning the desirability of a national enquiry in Brazil that would study the relationship between work and worker's health. This enquiry would supply data to bolster social partner's actions in their diverse environments, such as collective bargaining and public policies. Better understanding the determinant factors in the health-sickness process provides essential knowledge for curbing ever increasing work-related suffering, sickness and accidents. One should not only focus on the consequences, but also on the causes of these problems. We based our approach on the European Working Conditions Survey (EWCS), which has been implemented in all EU countries since 1990. This survey allows a better understanding of how varying work aspects can impact worker's health and has become essential reference when developing public policies seeking to improve living conditions for European workers.

Keywords: Worker's Health; Worker's Health Enquiry; Psychosocial Risks.
Embora o trabalho - atividade central na vida do ser humano - seja extremamente valorizado no contexto da sociedade capitalista, nem todas as suas dimensões são explicitadas e discutidas. Ao contrário, observa-se forte resistência social em reconhecer que seu exercício pode resultar em sentimentos de satisfação, realização e prazer, mas também pode ter como consequência mal-estar, doenças e acidentes (Dejours, 1986). Tal resistência, devida a diversos interesses e poderes envolvidos, tem levado a sociedade a ocultar o adoecimento no trabalho e culpabilizar e responsabilizar o sujeito pela "sua" doença (Maeno; Paparelli, 2013).

Para que as dimensões da satisfação, da realização e do prazer no trabalho possam prevalecer, é necessário trazer para o centro do debate os determinantes sociais do mal-estar no trabalho (Buss; Pellegrini Filho, 2007), buscando compreender de quais sofrimentos falam os trabalhadores ${ }^{1}$ - isto é, conhecer como o cotidiano do trabalho, que passa por forte processo de precarização, flexibilização, intensificação, crescente desemprego e insegurança (Cardoso, 2014; Neffa, 2015; Rosso, 2008), tem influenciado a vida e a saúde do trabalhador (Silva, 2011).

Para entender como a atividade de trabalho é realizada, torna-se fundamental conhecer de forma detalhada a gestão, a organização, as condições e as relações de trabalho em cada setor, em cada célula, em cada posto de trabalho - conhecer como os indivíduos enfrentam os riscos, as doenças e os acidentes relacionados ao trabalho. Há maneiras diferentes e complementares de produção de tais conhecimentos, como os estudos de caso, as observações nos locais de trabalho, a realização de entrevistas com os trabalhadores e a realização de pesquisas nacionais (Guèrin et al., 2004; Vilela et al., 2012). Neste artigo, a proposta é abordarmos essa última forma, elaborando reflexões que possam contribuir para a discussão e construção de uma pesquisa nacional, no Brasil, que explicite os determinantes da relação saúde-doença. 
Para realizar tal reflexão, será utilizado a European Working Conditions Survey (EWCS), aplicada nos países da União Europeia (UE) desde 1990, que traz informações sobre como as diferentes dimensões do trabalho vêm impactando a saúde dos trabalhadores.

\section{Informações sobre saúde e trabalho no Brasil}

Mas qual é a necessidade de uma pesquisa nacional se já há no Brasil aquelas que investigam algumas dimensões do trabalho e outras que se debruçam sobre a doença dos trabalhadores? A necessidade se explica pelo fato de não existir uma pesquisa com abrangência nacional que tenha como objetivo principal elucidar a relação entre esses dois aspectos, deixando uma lacuna de conhecimento sobre a vinculação entre trabalho e saúde.

Por exemplo, no que se refere às informações sobre os acidentes de trabalho, o Ministério do Trabalho e Previdência Social (MTPS) registrou 717.9 mil casos em 2013, sendo que os acidentes típicos, decorrentes da atividade profissional realizada, responderam por $77,32 \%$ do total das ocorrências (Brasil, 2013). Cabe lembrar que os indicadores sistematizados pelo MTPS foram concebidos para subsidiar a concessão de benefícios previdenciários aos trabalhadores regidos pela Consolidação das Leis do Trabalho (CLT), não incluindo ocorrências que acometem os informais que, por sua vez, representam quase metade da massa de trabalhadores (Amorim; Corseuil, 2016). Além disso, temos que considerar o elevado percentual de subnotificação acerca dos registros de acidentes, impedindo uma análise precisa sobre a abrangência e a frequência das ocorrências.

Em 2015, o Instituto Brasileiro de Geografia e Estatística (IBGE) divulgou os resultados da Pesquisa Nacional de Saúde (PNS), chamada de Percepção do estado de saúde, estilos de vida e doenças crônicas, tendo o objetivo de subsidiar a formulação de políticas públicas nas áreas de promoção, vigilância e atenção à saúde do Sistema Único de Saúde (SUS). Um dos temas abrangidos por ela diz respeito aos acidentes de trabalho, que - de acordo com a declaração dos entrevistados, incluindo aqueles com contrato de trabalho precário - contabilizaram aproximadamente cinco milhões de ocorrências, quantia muito maior do que as divulgadas pelo MTPS para o mesmo ano. Apesar das diferenças metodológicas impossibilitarem uma comparação simétrica dos dois levantamentos, seus resultados explicitam a inexistência de uma fonte estatística que possibilite sistematizar a real abrangência dos acidentes de trabalho e sua frequência no Brasil (Fundacentro, 2015). Além disso, é importante ressaltar que tais pesquisas não trazem informações sobre o processo de trabalho, mas apenas sobre o resultado final, ou seja, o acidente e a doença.

A PNS revelou ainda que, no Brasil, 2,4\% dos trabalhadores entrevistados tiveram diagnóstico médico de distúrbios osteomusculares relacionados ao trabalho (Dort), 6,2\% dos entrevistados haviam recebido diagnóstico de depressão e 13,7\% declararam consumo abusivo de álcool (IBGE; Fiocruz, 2015). Informações muito relevantes, mas que não nos informam sobre como a remuneração, a jornada de trabalho ou as demais condições laborais influenciaram no adoecimento desses trabalhadores.

Em relação às investigações que analisam algumas dimensões do trabalho e do emprego como a Pesquisa de Emprego e Desemprego (PED), realizada pelo Departamento Intersindical de Estatística e Estudos Socioeconômicos (Dieese) e pela Fundação Sistema Estadual de Análise de Dados (Fundação Seade) -, observa-se, por exemplo, que a proporção de ocupados que trabalharam mais do que a jornada legal de 44 horas semanais em julho de 2016 chegou a 37,8\% na região metropolitana de Fortaleza e $28,1 \%$ na de São Paulo (Dieese; Fundação Seade, 2012). No entanto, tal pesquisa não fornece informações que permitam problematizar de que maneira esse trabalho em excesso pode impactar a saúde dos trabalhadores (Cardoso, 2013; Rosso, 2008).

Ainda de acordo com a PED, o tempo médio de procura por uma nova ocupação nas regiões metropolitanas pesquisadas foi de 36 semanas no primeiro semestre de 2016, num contexto em que a taxa média de desemprego no mesmo período foi de 11,3\% (Dieese; Fundação Seade, 2012; IBGE; Fiocruz, 2015). Mas como o medo de perder o emprego 
ou o longo tempo na situação de desemprego têm impactado a saúde dos trabalhadores? $\mathrm{Na}$ impossibilidade de se comparar a PED, ou mesmo a Pesquisa Mensal de Emprego (PME), feita pelo IBGE, com a PNS, dado que suas metodologias e amostras são diferentes, informações sobre a relação entre trabalho e saúde dos trabalhadores não são identificadas, apesar das evidências já ressaltadas por diversos autores (Cardoso, 2014; Dejours, 1986; Rosso, 2008; Silva, 2015).

No Brasil, portanto, existem importantes pesquisas que analisam o emprego e o desemprego, como é o caso da PED e da PME, mas não examinam a saúde do trabalhador. Por outro lado, há pesquisas e levantamentos realizados pelo Ministério da Saúde e IBGE - a PNS - e pelo MTPS - o Anuário Estatístico da Previdência Social (Aeps) - que nos trazem informações epidemiológicas de grande valia, mas que se referem apenas superficialmente à atividade de trabalho. Tal realidade impossibilita a compreensão da relação entre trabalho e saúde dos trabalhadores, não contribuindo, por sua vez, para que os atores sociais tenham conhecimentos sobre os determinantes e causas do processo de adoecimento (Cardoso et al., 2015).

\section{EWCS: contribuições para a compreensão da relação entre trabalho e saúde do trabalhador}

Para contribuir com a discussão sobre a construção de uma pesquisa no Brasil, serão analisados alguns resultados da EWCS, realizado pela Fundação Europeia para a Melhoria das Condições de Vida e de Trabalho (Eurofound). ${ }^{2}$ A escolha dessa pesquisa levou em consideração não apenas seu conteúdo, mas também sua abrangência, bem como seu objetivo de produzir indicadores sobre os determinantes do processo saúde-doença dos trabalhadores em diferentes países para a criação de políticas públicas que promovam melhores condições laborais, contribuindo para o desenvolvimento da política europeia (Eurofound, 2017).

Realizada a cada cinco anos desde 1990, essa pesquisa domiciliar amostral tem sua abrangência expandida de acordo com a entrada de novos países no bloco europeu. ${ }^{3}$ Em 2010, foram 44 mil trabalhadores entrevistados num universo de 235 milhões, abrangendo 34 países: 27 Estados-membro da UE, cinco países candidatos à União e ainda a Suíça e a Noruega.

Os temas presentes no EWCS são os seguintes: contexto profissional; horário de trabalho; intensidade de trabalho; fatores físicos; fatores cognitivos; fatores psicossociais; saúde e bemestar; competências, formação e perspectivas de carreira; organização do trabalho; relações sociais; realização profissional; violência, assédio e discriminação; conciliação da vida profissional com a vida familiar; e segurança financeira. É importante ressaltar que, a cada ano, novas questões são observadas nos questionários, algo feito com a finalidade de melhor compreender um evento conjuntural importante ou mesmo incluir novos temas ou detalhar outros. Em 2010, por exemplo, foram incluídas novas questões para identificar os impactos da desaceleração econômica nas condições de trabalho (Eurofound, 2012).

Apesar de relativamente recente, o EWCS teve como referência uma das mais importantes e antigas pesquisas francesas elaborada no final dos anos 1970. Trata-se da enquete Conditions de Travail (Pesquisa sobre Condições de Trabalho), realizada a cada sete anos tendo como objetivo conhecer a realidade das circunstâncias laborais, avaliando sua evolução e produzindo subsídios para orientar

2 A Eurofound é uma agência tripartite da União Europeia, criada em 1975, que tem como principal objetivo subsidiar os países aderentes ao bloco no desenvolvimento de políticas públicas tendo em vista a melhora das condições de vida e trabalho dos cidadãos europeus. Para tal, diversos instrumentos e pesquisas foram criados pela instituição, entre eles a European Working Conditions Survey (EWCS), que será utilizado neste artigo, as European Company Surveys (ECS) e as European Quality of Life Surveys (EQLS).

3 Trata-se de uma investigação realizada pela Gallup Europe. Fazem parte da amostra as pessoas com idade igual ou superior a 15/16 anos que estão empregadas. Na maior parte dos países, a amostra é de 1.ooo pessoas - mas, por exemplo, na Alemanha e na Turquia contabiliza-se 2.0oo pessoas; Itália, Polônia e o Reino Unido têm amostra de 1.50o pessoas. Na Bélgica são 4.ooo pessoas, na França, 3.0oo, e na Eslovênia ,1.400. 
as decisões dos diferentes atores sociais, sobretudo no que se refere à elaboração de políticas públicas (Volkoff, 1991).

Para este artigo, apesar da evidência de que praticamente todas as dimensões do trabalho impactam a saúde do trabalhador, considerando seus aspectos físicos, mentais e emocionais, foi necessário fazer um recorte, sendo selecionados aspectos próximos à realidade dos trabalhadores brasileiros e aqueles que têm sido mais destacados como determinantes no processo de adoecimento no contexto atual (Cardoso et al., 2015; Clot, 2011; Dejours, 2007; Gollac, 2005; Maeno; Paparelli, 2013; Silva, 2011). Também foi dada prioridade àqueles dados passíveis de análise entre os anos de aplicação da enquete, mesmo que as diferenças ao longo do tempo, assim como entre países, precisem ser analisadas com cautela, pois os dados não provêm de amostragem (Eurofound, 2012). Neste estudo serão priorizados os resultados da pesquisa realizada em 2010, em diálogo, quando possível, com as informações já disponíveis do sexto EWCS, que foi a campo durante o ano de 2015 (Eurofound, 2007, 2012, 2015, 2017).

Para o agrupamento dos temas a serem analisados, também foram utilizados como referência os indicadores sobre riscos psicossociais no trabalho (RPS). ${ }^{4}$ Definidos como "riscos para a saúde mental, física e social, causados pelas condições de emprego e pelos fatores organizacionais e relacionais susceptíveis de interagir com o funcionamento mental" (Gollac; Bodier, 2011, p. 13), os indicadores criados buscam compreender como as diferentes dimensões do trabalho influenciam e/ou determinam o processo de adoecimento.

Os indicadores abordam as seguintes características: (1) exigências do trabalho incluindo questões sobre período de labor, intensidade, complexidade e ritmo, bem como as metas e os prazos estipulados pela gestão; (2) exigências emocionais, que implicam a necessidade de o trabalhador controlar ou ocultar emoções na relação com o público ou no contato com o sofrimento e o medo no trabalho; (3) autonomia ou margem de manobra, indicador que demonstra a participação, ou não, dos trabalhadores em decisões importantes sobre seu trabalho, os objetivos da atividade ou as pausas, englobando ainda a questão da previsibilidade do trabalho; (4) relações sociais de trabalho, que indicam quais ligações se estabelecem entre os trabalhadores, entre estes e a hierarquia e entre eles e os usuários, inquirindo ainda se há assédio moral, organizacional ou sexual embutido nessas relações; (5) conflitos de valores, que dizem respeito ao sofrimento ético no trabalho em função da obrigatoriedade de realização de tarefas que se oponham aos valores sociais ou profissionais dos trabalhadores, bem como o sentimento de realização de um trabalho inútil; e (6) insegurança na situação de trabalho e emprego, que envolve o risco de perdêlo, ter o salário reduzido ou vivenciar mudanças não previstas (Cardoso, 2014).

\section{Trabalho e saúde do trabalhador}

\section{Tempo de trabalho: normal, extraordinário e ilegal}

A jornada laboral impacta diretamente a saúde dos trabalhadores, tanto em nível físico como mental (Cardoso, 2009; Rosso, 2008). Diante da pressão do empregador para que estes estejam cada vez mais à disposição do trabalho, o tempo dedicado a essa atividade costuma extrapolar, e muito, a jornada normal e mesmo a extraordinária - de forma que a mensuração do tempo total de trabalho deve considerar ainda a "jornada ilegal”, ou seja, aquele tempo em que o empregado continua conectado e realizando o trabalho mesmo após finalizar sua jornada contratual. Essa prática é facilitada pela difusão das novas tecnologias de informação e comunicação (Cardoso, 2009).

\footnotetext{
4 Os indicadores foram criados pelo Collège d’Expertise, em 2008, por demanda do Ministério do Trabalho francês, após diversos casos de suicídios relacionados ao trabalho. Esses indicadores têm sido amplamente utilizados por pesquisadores de vários países da Europa, bem como do Canadá e do Japão. Há um grupo, denominado Approche Juridique Comparée des Risques Psychosociaux au Travail (Comparisk), criado para analisar os aspectos jurídicos dos riscos psicossociais no trabalho desses países (Lerouge, 20og). Na França, foi criada a primeira pesquisa específica sobre riscos psicossociais no trabalho, coordenada pela Direction de l’Animation de la Recherche, des Études e des Statistiques (Dares), tendo os primeiros resultados sido divulgados em 2017 (Dares, 2017).
} 
Gráfico I - Qual é a carga horária semanal do seu trabalho principal? (1991-2010)

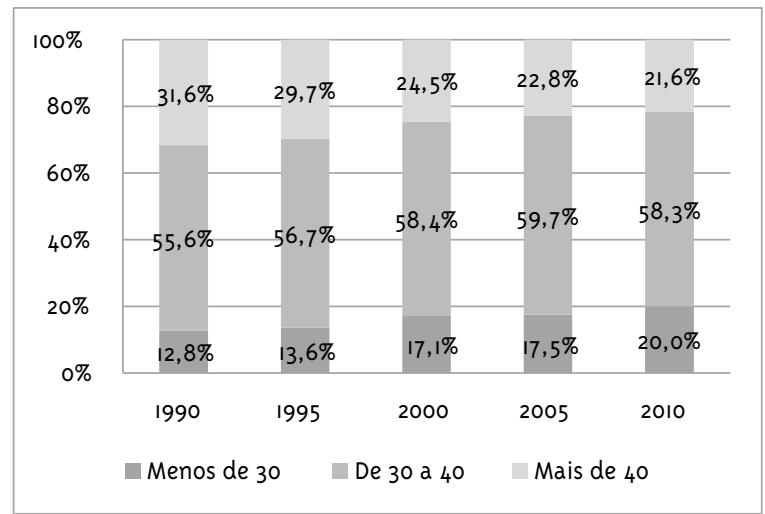

No Gráfico 1, vemos que o contingente de pessoas que trabalhava de 30 a 40 horas por semana em seus empregos cresceu $5 \%$ entre 1990 e 2000 , permanecendo praticamente estável desde então. Nesse mesmo período, mais pessoas disseram trabalhar menos de 30 horas semanais e, inversamente, houve redução daquelas que laboram mais de 40 horas. A redução da carga horária ao longo do tempo, mesmo que em boa parte seja involuntária, no caso dos que trabalham até 30 horas, nos ajuda a compreender o pequeno aumento dos que afirmam cumprir horário de trabalho que se adapta "bem" aos compromissos familiares (Gráfico 2).

\section{Gráfico 2 - Em que medida o horário de trabalho se adapta a seus compromissos familiares ou sociais fora do trabalho? (2000-2010)}

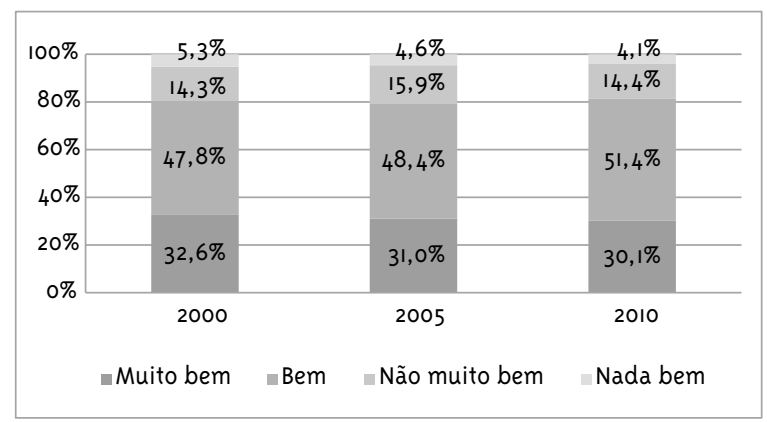

Os resultados de 2015 do EWCS mostram que, mesmo que $58 \%$ dos entrevistados confirmem que o horário de trabalho está de acordo com suas preferências, $13 \%$ gostariam de aumentá-lo e $28 \%$ de reduzi-lo. No primeiro caso, o resultado dialoga, mais uma vez, com o aumento do percentual de trabalhadores com emprego em tempo parcial de até 30 horas por semana (Eurofound, 2017). Esse mesmo grupo de trabalhadores vale ressaltar, está mais propenso a precariedade laboral e piores condições laborais que os demais, o que certamente tem impacto negativo em sua saúde (Eurofound, 2015). Em relação aos que gostariam de reduzir a carga horária semanal, esse resultado se deve, em parte, ao fato de que trabalhar " 48 horas ou mais" ainda é uma realidade para $12 \%$ dos entrevistados (Eurofound, 2017).

Ao se tratar do tempo de trabalho entre homens e mulheres, a desigualdade entre os gêneros teve ligeira queda, desde 2005 , devido à carga horária semanal dos homens ter diminuído mais rapidamente que a das mulheres. Os homens trabalham, em média, 39 horas por semana, enquanto as mulheres laboram 33 horas. Entretanto, a história se inverte quando são contabilizadas as horas de trabalho não remuneradas, nas quais as mulheres despendem o dobro do tempo que os homens no cuidado com os filhos e nas demais atividades domésticas (Eurofound, 2015). Tais diferenças - vale ressaltar - resultam também em formas diferentes de adoecimento que, por sua vez, demandam políticas públicas diferenciadas.

No tocante à invasão do trabalho no tempo (e espaço) de não trabalho, a pesquisa de 2015 mostra que $45 \%$ dos entrevistados dizem ter trabalhado durante seu tempo livre nos últimos 12 meses, sendo que $7 \%$ o fizeram várias vezes por semana e $13 \%$ várias vezes por mês (Eurofound, 2015). Além disso, $14 \%$ dos trabalhadores dizem que continuam a se preocupar "sempre" ou "quase sempre" com o trabalho durante o tempo livre, e $21 \%$ se sentem "sempre" ou "quase sempre" demasiado cansados para executar algumas das tarefas domésticas necessárias. Finalmente, $11 \%$ dos entrevistados declaram que sua jornada de trabalho os impede "sempre" ou "quase sempre" de dedicar tempo à família (Eurofound, 2015). Ou seja, há redução daqueles que trabalham além das 48 horas semanais, mas, ao mesmo tempo, um elevado percentual de entrevistados relata trabalhar em seu tempo livre. 


\section{Exigências no trabalho: intensidade e ritmo de trabalho}

Outro fator determinante no processo saúdedoença refere-se às exigências no trabalho, englobando os aspectos físicos, mentais e emocionais (Fernex, 1998). Dentre elas, temos o ritmo de trabalho, os prazos, a existência de interrupções frequentes e perturbadoras e o trabalho em excesso (Eurofound, 2017). Além disso, há o fato de o trabalhador ter que lidar com várias fontes de pressão ao mesmo tempo, sejam elas decorrentes das metas e objetivos, das demandas de outros trabalhadores, da coordenação ou do público - sendo que, quanto maior for o número de fatores que estabelecem o ritmo de trabalho, maiores serão as exigências colocadas e, consequentemente, maior é o potencial de impacto negativo do trabalho na saúde (Eurofound, 2012). Na pesquisa de 1990, os trabalhadores que disseram realizar suas atividades com mais rapidez em pelo menos um quarto do tempo somavam $47,2 \%$. Já na de 2010, 60,2\% das respostas foram nessa direção (Eurofound, 2012).

Ainda em relação à pesquisa de 2010 , é interessante observar que, apesar de mais trabalhadores dizerem que estão realizando seu trabalho com mais rapidez, $25 \%$ dos entrevistados ressaltam que não têm tempo suficiente para terminar o trabalho (Eurofound, 2012).

Gráfico 3-Com que frequência seu trabalho demanda atividades que precisam ser realizadas com muita rapidez? (1991-2010)

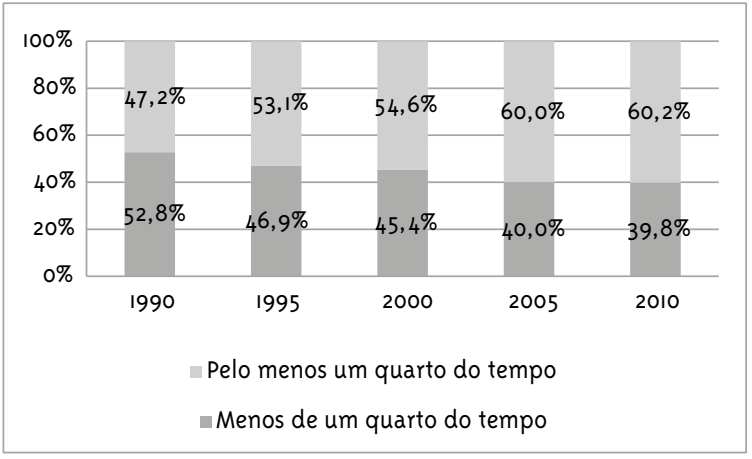

O relatório divulgado em 2015 estima que o trabalho intenso seja uma realidade para muitos trabalhadores, dado que $36 \%$ trabalham "sempre" ou "quase sempre" com prazos curtos; $33 \%$ declararam trabalhar em ritmo acelerado. Além disso, esse mesmo percentual de entrevistados declara sofrer com interrupções frequentes e perturbadoras (Eurofound, 2015).

Um dos problemas decorrentes desse aumento de intensidade e ritmo de trabalho, de acordo com Boisard et al. (2002), é a dúvida, por parte do trabalhador, entre atender às metas de produção e ao desejo de preservar a saúde, dado que a urgência acaba levandoos a adotar a maneira mais rápida de trabalhar, que nem sempre é a melhor para sua saúde. De fato, a intensificação do trabalho torna quase impossível a adoção de práticas indispensáveis para a preservação da saúde, como "mudar de posição, respirar por um momento, organizar o posto de trabalho, escolher o instrumento adequado, informar-se corretamente, buscar a cooperação no momento oportuno, anteciparse para evitar ou se preparar para as situações de urgência" (Boisard et al., 2002, p. 46, tradução nossa). ${ }^{5}$ Sendo assim, essas fortes pressões sobre o ritmo são associadas a uma percepção mais pessimista da relação entre trabalho e saúde (CEE, 2001)

A relação entre a queda no tempo de trabalho e o aumento do ritmo de trabalho poderia nos levar a pensar que a redução da jornada laboral estaria sendo "compensada" por um aumento no ritmo e na intensidade do trabalho, apesar de não ser possível fazer comparação direta entre as duas questões. Entretanto, o relatório divulgado em 2017 pela Eurofound ressalta que os trabalhadores que realizam jornadas de trabalho longas declararam também que o trabalho é intenso, o que leva à conclusão de que o trabalho intenso independe da jornada laboral, mas se apoia na forma como o trabalho é gerido e organizado (Gaulejac, 2005).

\section{Autonomia e apoio social}

A consideração do grau de autonomia também é essencial para a discussão da saúde no trabalho.

\footnotetext{
5 No original: “changer de position, «souffler» un instant, organiser son poste de travail, choisir l'outil ou le document adapté, s'informer correctement, s'assurer des coopérations utiles au bon moment, anticiper pour éviter ou se préparer aux situations d'urgence”.
} 
Estudos realizados por Theorell e Karasek (1996) e Siegrist e Rödel (2006), comprovam que a associação entre forte pressão, fraca autonomia, fraca sustentação social e ausência de reconhecimento constitui fator de risco e tensão, gerando insatisfação em relação às condições de trabalho, podendo levar ao adoecimento. A autonomia não só possibilita que o trabalhador se adapte às condições de trabalho, sem colocar em risco sua saúde, como permite o uso da criatividade, do conhecimento e de sua experiência, essenciais para a saúde mental e o prazer no trabalho.

Questionados sobre a autonomia, na pesquisa de 2010, 70\% dos trabalhadores disseram poder escolher o grau de rapidez despendido no trabalho, $66 \%$ a ordem em que realizam a atividade e $67,3 \%$ o método de trabalho. 0 percentual dos respondentes que não têm possibilidade de escolher ou modificar a execução de suas atividades, apesar de menor, é bem expressivo, em especial no quesito "ordem das tarefas”, chegando a 34\% (Eurofound, 2012). Como dito anteriormente, mesmo que não se possa fazer comparação direta entre duas perguntas, é curioso observar que - ao mesmo tempo em que 70\% dos entrevistados dizem ter autonomia para definir o ritmo de trabalho -, a cada ano da pesquisa, mais trabalhadores ressaltam trabalhar de forma intensa uma parte do tempo. Assim como em todos os outros indicadores, o percentual de respostas positivas, no que se refere à autonomia, depende do setor de atividade, do tamanho da empresa e da função, bem como da idade e do sexo (Eurofound, 2017).

Analisando o Gráfico 4, vemos que o grau de autonomia diminui consideravelmente quando se trata da real possibilidade de intervir no trabalho. Somando aqueles que "nunca" podem influenciar nas decisões importantes com os que responderam "às vezes", chega-se a mais da metade $(59,8 \%)$ dos entrevistados. Já no que diz respeito à definição dos objetivos de trabalho, menos da metade dos entrevistados $(46,8 \%)$ responderam que "sempre" são consultados. Como ressaltam Gollac e Coninck (2006), um dos fatores preponderantes no processo de intensificação está relacionado à gestão por metas e objetivos, sendo que os trabalhadores podem até definir a maneira de atingi-los, mas não os objetivos propriamente.

Um resultado positivo é que grande percentual de entrevistados respondeu que recebe apoio dos colegas de trabalho quando necessita. Afinal, o apoio social no local de trabalho contribui positivamente para o não adoecimento dos trabalhadores (Siegrist; Rödel, 2006).

\section{Gráfico $_{4}$ - Selecione a resposta que melhor descreva as relações sociais no seu trabalho (2010)}

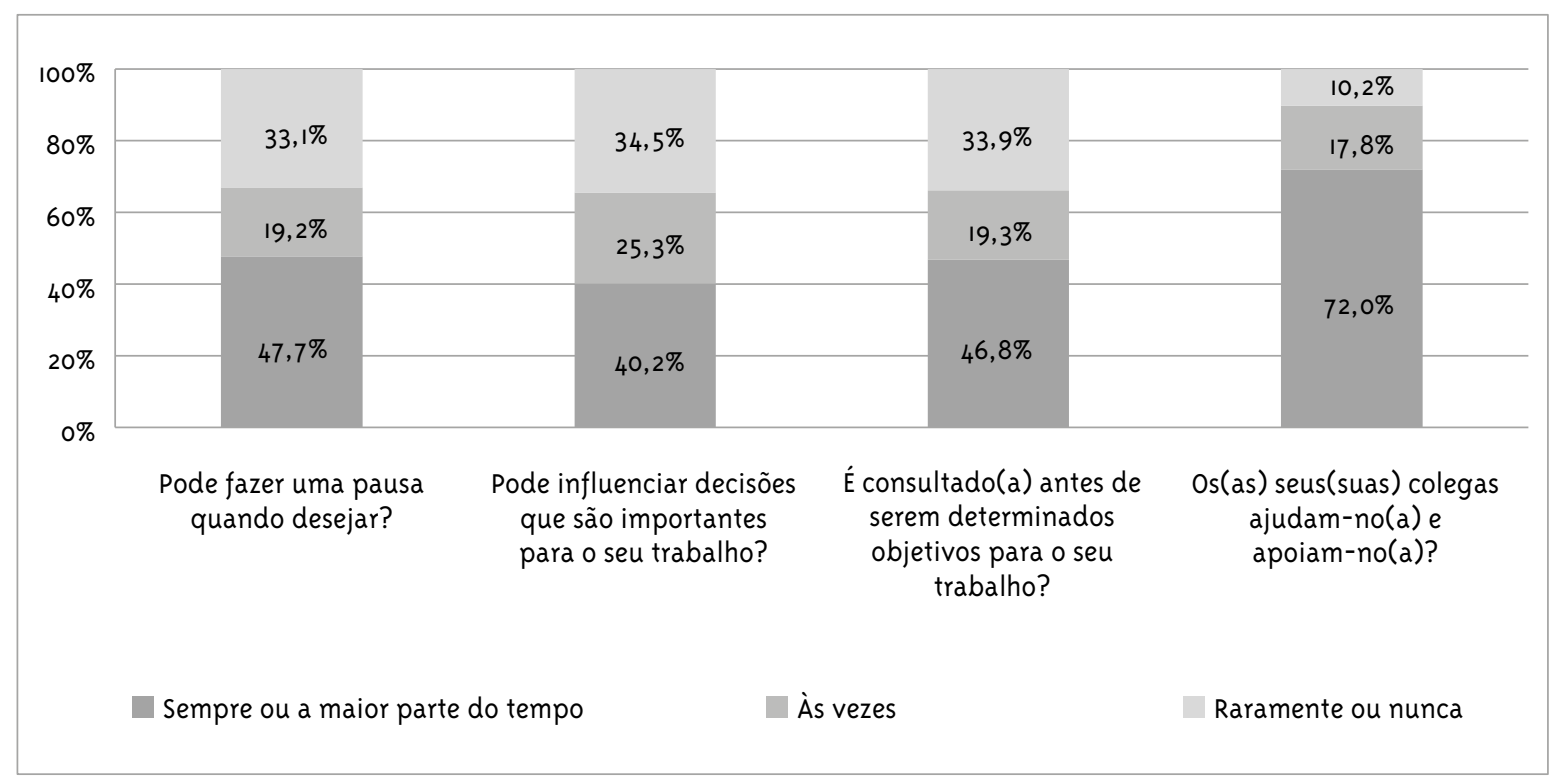




\section{Violência no local de trabalho}

Os trabalhadores têm sido expostos, em diferentes situações do trabalho, a diversas formas de violência, fruto da negligência em relação à preservação de sua saúde e sua vida (Silva, 2011). O EWCS pesquisa a incidência de vários tipos de comportamentos considerados "adversos", como a violência física e verbal, o assédio moral/organizacional e o assédio sexual, além das ameaças, intimidações ou situações humilhantes e discriminatórias a que são submetidos os trabalhadores. Em 2015, 7\% dos entrevistados declararam já ter sofrido com tipos de comportamento (Eurofound, 2017).

Outra forma de violência refere-se ao conflito ético que pode ocorrer entre uma demanda de trabalho e os valores dos trabalhadores, como enganar um cliente, vender um produto para quem não precisa, usar matéria-prima sem qualidade, não dar a atenção necessária a um paciente e demitir um trabalhador. Mesmo que a maior parte dos entrevistados, em 2010, compreenda que a atividade laboral "raramente" ou "nunca" conflita com seus valores pessoais (79,7\%), é expressiva a porcentagem $(20,3 \%)$ dos que responderam que "sempre", a "maior parte das vezes" ou "às vezes" sentem seus valores afetados pelo trabalho (Eurofound, 2012). 0 conflito de valores deixa os trabalhadores angustiados e mesmo desanimados com seu trabalho, algo que pode refletir negativamente em sua saúde e no desejo de trabalhar.

\section{Riscos físicos}

Realizar uma análise que considere os riscos psicossociais no trabalho não significa abandonar os riscos "tradicionais", dado que eles ainda acometem um percentual elevado de trabalhadores, nos mais diferentes setores. Analisando os resultados das pesquisas realizadas em 2005, 2010 e 2015, temos uma pequena redução do percentual dos trabalhadores expostos a vibração em ao menos um quarto da jornada de trabalho (24\%, $23 \%$ e $20 \%$, respectivamente) e ruídos (30\%, 29\% e $28 \%$ ). Mas observamos também um ligeiro aumento dos trabalhadores expostos a produtos químicos (14\%, $15 \%$ e $17 \%$, respectivamente) e materiais capazes de transmitir doenças infecciosas ( $9 \%, 11 \%$ e $13 \%)$ (Eurofound, 2017).

No que diz respeito às informações de 2010 , apesar de a maioria dos entrevistados dizer que "quase nunca" realiza suas atividades laborais em posições dolorosas ou fatigantes, é considerável o percentual daqueles que declararam realizar suas atividades nessas condições entre um quarto e três quartos do tempo. Realidade que não sofre modificação quando se analisam os dados de $\mathbf{2 0 1 5}$. Ainda de acordo com esta pesquisa, em torno de $35 \%$ dos entrevistados afirmam que seu trabalho envolve transporte ou deslocamento de cargas pesadas (Eurofound, 2017).

Retomando a pesquisa de 2010, como pode ser visto no Gráfico 5, 33\% dizem que "quase todo o tempo" realizam movimentos repetitivos com mãos e braços, percentual que chega a 30,5\% para os que os realizam entre um quarto e três quartos do tempo. Esse percentual sobe para $63,4 \%$, quando se refere à exposição durante um quarto do tempo ou mais (Eurofound, 2012).

\section{Gráfico 5 - Em relação às condições físicas do trabalho (2010)}

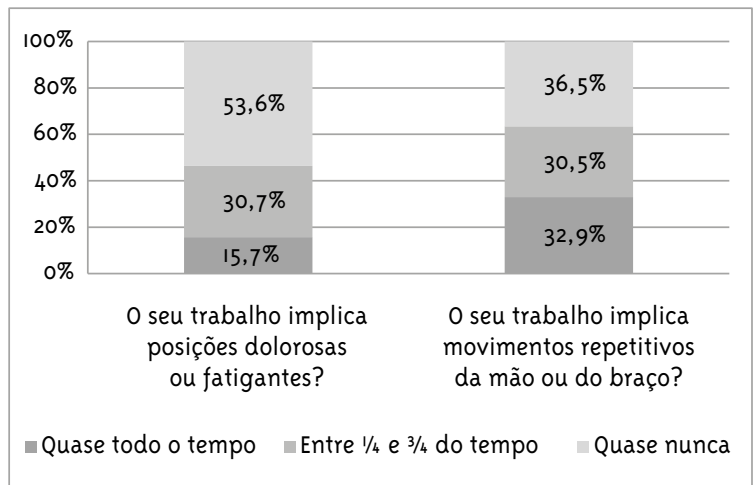

\section{Relação esforço-recompensa}

Os Gráficos 6 e 7 trazem algumas informações sobre a relação esforço-recompensa - que, como frisado por Siegrist e Rödel (2006), representa o quanto o trabalhador se sente recompensado pelo trabalho (esforço) realizado. Tal recompensa pode se realizar de maneira verbal, financeira, por uma promoção, pela segurança no emprego e por 
boas condições de trabalho. A ideia é que, quando o empregado não se sente recompensado, tem a sensação de que "não valeu a pena", que abriu mão de seu tempo por nada e, consequentemente, sentimentos de desânimo, injustiça ou mesmo raiva podem aparecer, influenciando negativamente sua saúde, sobretudo quando não há possibilidade de mudar de setor ou trabalho.

Em relação à remuneração, na pesquisa de 2010, apesar de $41 \%$ explicitarem que se sentem bem remunerados pelo trabalho que desenvolvem, quase $61 \%$ dizem que, no caso de uma doença de longa duração, não estariam cobertos financeiramente. Além disso, 30,9\% não consideram que são bem pagos pelo trabalho realizado (Eurofound, 2012).

Outra informação relevante se refere à segurança no emprego, dado que o medo de ficar desempregado contribui negativamente para o processo saúdedoença, como dito anteriormente. Na comparação entre as últimas pesquisas realizadas, vemos que, em 2005, 14\% dos trabalhadores entrevistados "concordavam" ou "concordavam plenamente" com a possibilidade de perderem o emprego nos próximos seis meses. Já nas pesquisas de 2010 e 2015, esse percentual ficou em 16\% (Eurofound, 2017).

\section{Trabalho e saúde}

Outra importante informação captada pela enquete é a percepção dos trabalhadores sobre sua saúde. De acordo com a pesquisa de 2015, um em cada dez trabalhadores (10\%) diz estar "bastante mal" ou "muito mal" informado sobre os riscos para sua saúde relacionados ao desempenho de sua função (Eurofound, 2015), sendo que, quanto menor a empresa, maior o percentual daqueles que se declaram mal informados.

A análise dos dados referentes aos anos de 1990, 1995 e 2000 revela que os cinco problemas mais citados pelos trabalhadores são os mesmos: dor nas costas, estresse, fadiga generalizada, dores musculares no braço e mãos e dor de cabeça (DaubasLetourneux; Thébaud-Mony, 2002). Em 2005, dos 17 sintomas que aparecem na pesquisa, a maior parte dos trabalhadores assinalou de dois a seis, entre eles: dores nas costas, dores musculares, sintomas de cansaço, irritabilidade, insônia, ansiedade e estresse, dores de cabeça e estômago, problemas na vista, na audição e na pele, dificuldade respiratória, alergias e problemas cardíacos (Eurofound, 2007).

Um dado interessante a observar é a grande quantidade de trabalhadores que considera que o trabalho não afeta sua saúde, sendo que, para 2010, o percentual se aproxima de 68\% (Gráfico 6). Isso nos faz refletir sobre como os trabalhadores compreendem seu sofrimento e adoecimento e, sobretudo, o que eles entendem serem suas causas e determinantes.

\section{Gráfico 6 - 0 seu trabalho afeta a sua saúde? (2010)}

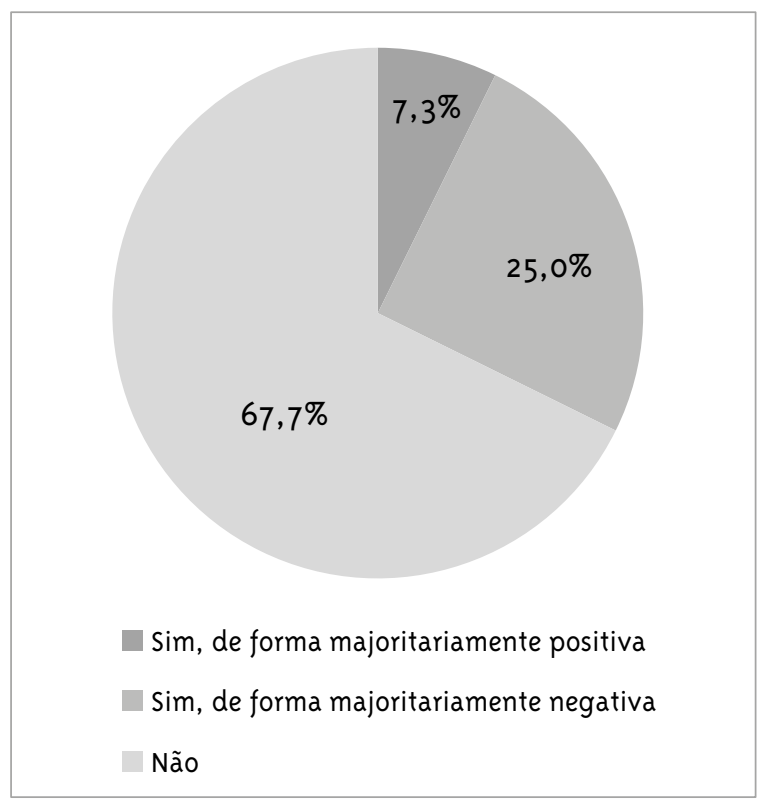

Finalmente, o Gráfico 7 revela um novo fenômeno. Se, tradicionalmente, dois bons indicadores de adoecimento no trabalho eram o absenteísmo e as licenças-saúde, hoje em dia, em função do medo de perder o emprego e da forte pressão vinda não apenas da coordenação, mas também dos colegas de trabalho, laborar, mesmo estando doente - o chamado "presenteísmo" - é cada vez mais comum.

Questionados se, nos últimos 12 meses, trabalharam doentes, quase $40 \%$ dos entrevistados responderam positivamente (Eurofound, 2012). Os trabalhadores escondem dos colegas - e muitas vezes de si mesmos - o mal-estar, o adoecimento e até pequenos acidentes. Essa conduta pode se estender até o agravamento dos sintomas, momento em que a 
necessidade de assistência e afastamento se impõe. O problema é que a busca tardia pelo tratamento demanda afastamentos mais longos, maiores encargos para os setores de previdência e saúde e, evidentemente, problemas para o trabalhador e sua família (Silva, 2015).

\section{Gráfico 7- Nos últimos 12 meses, você trabalhou estando doente? (2010)}

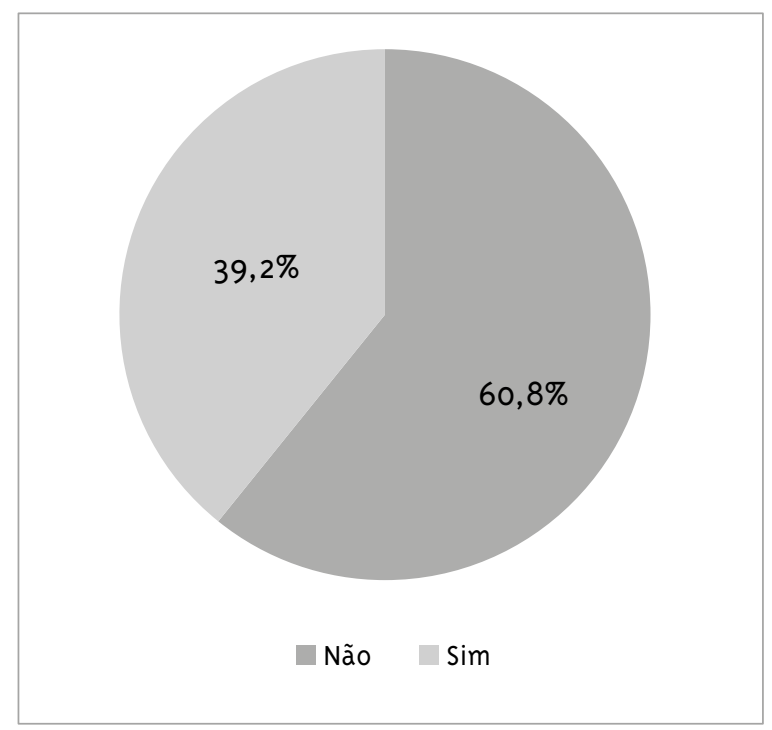

\section{Considerações finais}

As problematizações realizadas neste artigo tiveram como finalidade reforçar a importância das reflexões e discussões sobre a construção de uma pesquisa nacional, no Brasil, que identifique a relação entre trabalho e saúde do trabalhador; uma investigação que aporte conhecimentos sobre os determinantes do processo de adoecimento, subsidiando os diversos atores sociais, tanto no espaço micro, da negociação coletiva, como no macro, no qual se elaboram regras e legislações. Afinal, se a sociedade quer realmente reduzir o sofrimento, o adoecimento e os acidentes vinculados ao trabalho, não será suficiente continuar a agir, prioritariamente, sobre suas consequências (Cardoso et al., 2015). A legislação brasileira, e ainda mais a negociação coletiva, seguem tratando muito pouco das causas do adoecimento, ou seja, da gestão ou da organização laboral, assim como das relações que se estabelecem nos locais de trabalho, focando em ações a serem realizadas após o processo de adoecimento ou o acidente (Cardoso et al., 2015).

Também é importante considerar que, no Brasil, é muito difícil para o movimento sindical, e mesmo para os inspetores do trabalho, obter informações precisas sobre a atividade laboral. Por isso mesmo, uma pesquisa semelhante à realizada pelo Eurofound poderia aportar dados e subsídios importantes, além de tornar mais evidente o que se passa dentro dos locais de trabalho. A própria elaboração de uma pesquisa poderia se constituir num espaço de reflexão e construção interdisciplinar entre os diversos atores envolvidos, contribuindo para o debate sobre uma questão tão iminente e abrangente, mas ainda pouco discutida na sociedade brasileira, isto é, o trabalho como determinante no processo saúde-doença.

Uma pesquisa desse porte e com esse enfoque, intercruzando as diversas relações entre trabalho e saúde, serviria também para subsidiar e/ou aperfeiçoar políticas públicas, consolidando ações de saúde do trabalhador que vão desde a vigilância até a assistência em seu sentido amplo, buscando integrá-las aos serviços do SUS (Minayo-Gomez; Thedim-Costa, 1997). A incorporação dessa visão aos serviços básicos de saúde propiciaria uma investigação mais precisa das doenças ao considerar a atividade de trabalho dos sujeitos como possível determinante para o adoecimento dos trabalhadores. Essa mudança de perspectiva possibilitaria o combate eficaz às reais causas de certas ocorrências, impactando diretamente na redução dos custos dispendidos pelo Estado no acolhimento e tratamento dos trabalhadores adoecidos.

\section{Referências}

\section{AMORIM, B.; CORSEUIL, L. H. C. Análise da dinâmica do emprego setorial de 2014 a 2015.} Brasília, DF: Instituto de Pesquisa Econômica Aplicada, 2016. v. 23. (Série Nota Técnica). Disponível em: <https://bit.ly/2sxceFa>. Acesso em: 13 jul. 2018.

BOISARD, P. et al. Temps et travail: l'intensité du travail. Luxembourg: Fondation Européenne pour l'Amelioration des Conditions de Vie et de Travail, 2002. 
BRASIL. Ministério do Trabalho e Previdência Social. Anuário estatístico da previdência social 2013. Brasília, DF: Dataprev, 2013. Disponível em: <https://bit.ly/2eK6ogX>. Acesso em: 13 jul. 2018.

BUSS, P. M.; PELLEGRINI FILHO, A. A saúde e seus determinantes sociais. Physis, Rio de Janeiro, v. 17, n. 1, p. 77-93, 2007.

CARDOSO, M. C. A. Tempos de trabalho, tempos de não trabalho. São Paulo: Annablume, 2009.

CARDOSO, M. C. A. Organização e intensificação do tempo de trabalho. Sociedade e Estado, Brasília, DF, v. 28, p. 351-374, 2013.

CARDOSO, M. C. A. Indicadores sobre riscos psicossociais no trabalho. In: SILVEIRA, M. A. (Org.). Aspectos psicossociais e sustentabilidade em organizações: saúde, segurança e qualidade de vida no trabalho. Campinas: Centro de Tecnologia da Informação Renato Archer, 2014. p. 129-144.

CARDOSO, M. C. A. et al. Saúde do trabalhador no processo de negociação coletiva no Brasil. São Paulo: Departamento Intersindical de Estatística e Estudos Socioeconômicos, 2015 v. 76. (Série Estudos e Pesquisas).

CEE - CENTRE D'ÉTUDES DE EMPLOI. Contraintes de temps dans le travail et risques pour la santé en Europe. Quatre Pages, Paris, n. 47, 2001.

CLOT, Y. Trabalho e poder de agir. Revista Brasileira de Saúde Ocupacional, São Paulo, v. 36, n. 123, p. 150-152, 2011.

DARES - DIRECTION DE L'ANIMATION DE LA RECHERCHE, DES ÉTUDES E DES STATISTIQUES. Quelles sont les évolutions récentes des conditions de travail et des risques psychosociaux? Dares Analyses, Paris, n. 82, 2017. Disponível em: <https://bit.ly/2APs6ax>. Acesso em: 14 jul. 2018.

DAUBAS-LETOURNEUX, V.; THÉBAUD-MONY, A. Organisation du travail et santé dans l'Union Européene. Luxembourg: Eurofound, 2002.

DEJOURS, C. Por um novo conceito de saúde. Revista Brasileira de Saúde Ocupacional, São Paulo, v. 14, n. 54, p. 7-11, 1986.
DEJOURS, C. Conjurer la violence: travail, violence et santé. Paris: Payot \& Rivages, 2007.

DIEESE - DEPARTAMENTO INTERSINDICAL DE ESTATÍSTICA E ESTUDOS SOCIOECONÔMICOS; FUNDAÇÃO SEADE - FUNDAÇÃO SISTEMA ESTADUAL DE ANÁLISE DE DADOS. Pesquisa de emprego e desemprego. São Paulo, 2012. Disponível em: <https://bit.ly/2Mf1AMd>. Acesso em: 19 set. 2016 .

EUROFOUND - EUROPEAN FOUNDATION FOR THE IMPROVEMENT OF LIVING AND WORKING CONDITIONS. Fourth European Working

Conditions Survey. Luxembourg, 2007. Disponível em: <https://bit.ly/2TO6eU2>. Acesso em: 23 ago. 2016.

EUROFOUND - EUROPEAN FOUNDATION FOR THE IMPROVEMENT OF LIVING AND WORKING CONDITIONS. Fifth European Working Conditions Survey. Luxembourg, 2012. Disponível em: <https://bit.ly/2SV2vEo>. Acesso em: 14 jul. 2016.

EUROFOUND - EUROPEAN FOUNDATION FOR THE IMPROVEMENT OF LIVING AND WORKING CONDITIONS. Primeiras conclusões: sexto inquérito europeu sobre as condições de trabalho. Luxemburgo, 2015. Disponível em: <https://bit. ly/2sxL6G1>. Acesso em: 15 set. 2016.

EUROFOUND - EUROPEAN FOUNDATION FOR THE IMPROVEMENT OF LIVING AND WORKING CONDITIONS. Sixth European Working Conditions Survey. Luxembourg, 2017. Disponível em: <https:// bit.ly/2E5qwFs>. Acesso em: 13 jul. 2018.

FERNEX, A. Intensité du travail, définition, mesure, évolutions: premiers repérages. Études et Recherche, [S.l.], n. 169, 1998.

FUNDACENTRO - FUNDAÇÃO JORGE DUPRAT E FIGUEIREDO DE SEGURANÇA E MEDICINA DO TRABALHO. Acidentes de trabalho no Brasil em 2013: comparação entre dados selecionados da Pesquisa Nacional de Saúde do IBGE (PNS) e do Anuário Estatístico da Previdência Social (AEPS) do Ministério da Previdência Social. São Paulo, 2015.

GAULEJAC, V. La societe malade de la gestion: idéologie gestionnaire, pouvoir managérial et harcèlement social. Paris: Éditions du Seuil, 2005. 
GOLLAC, M. L'intensité du travail. Revue

Économique, Paris, v. 56, n. 2, p. 217-236, 2005.

GOLLAC, M.; BODIER, M. Mesurer les facteurs psychosociaux de risque au travail pour les maîtriser. Paris: Rapport du Collège d'Expertise sur le Suivi des Risques Psychosociaux au Travail, 2011.

GOLLAC, M.; CONINCK, F. Organisation et intensité du travail. Toulouse: Octares, 2006.

GUÈRIN, F. et al. Compreender o trabalho para transformá-lo. São Paulo: Blucher, 2004.

IBGE - INSTITUTO BRASILEIRO DE ESTATÍSTICA E GEOGRAFIA; FIOCRUZ FUNDAÇÃO OSWALDO CRUZ. Pesquisa Nacional de Saúde: percepção do estado de saúde, estilos de vida e doenças crônicas. Rio de Janeiro, 2015. Disponível em: <https://bit.ly/2sT9WBW>. Acesso em: 19 set. 2016

LEROUGE, L. Risques psychosociaux au travail: étude comparée Espagne, France, Grèce, Italie, Portugal. Paris: L'Harmattan, 2009.

MAENO, M.; PAPARELLI, R. O trabalho como ele é e a saúde mental do trabalhador. In: SILVEIRA, M. A. (Org.). Inovação para o desenvolvimento de organizações sustentáveis: trabalho, fatores psicossociais e ambiente saudável. Campinas: Centro de Tecnologia da Informação Renato Archer, 2013. p. 145-166.

MINAYO-GOMEZ, C.; THEDIM-COSTA, F. M. S. A construção do campo de saúde do trabalhador: percurso e dilemas. Cadernos de Saúde Pública, Rio de Janeiro, v. 13, p. 21-32, 1997. Suplemento 2.
NEFFA, C. J. O trabalho humano e sua centralidade. Ciências do Trabalho, São Paulo, n. 4, p. 7-26, 2015 .

ROSSO, D. S. Mais trabalho: a intensificação do labor na sociedade contemporânea. São Paulo: Boitempo, 2008.

SIEGRIST, J.; RÖDEL, A. Work stress and health risk behavior. Scandinavian Journal of Work, Environment \& Health, Helsinki, v. 6, n. 32, p. 473481, 2006.

SILVA, E. S. Trabalho e desgaste mental: o direito de ser dono de si mesmo. São Paulo: Cortez, 2011.

SILVA, E. S. Desemprego e desgaste mental: desafio as políticas públicas e aos sindicatos. Ciências do Trabalho, São Paulo, n. 4, p. 89-109, 2015 .

THEORELL, T.; KARASEK, R. A. Current issues relating to psychosocial job strain and cardiovascular disease research. Journal of Occupational Health Psychology, Washington, DC, n. 1, v. 1, p. 9-26, 1996.

VILELA, G. A. R. et al. Da vigilância para prevenção de acidentes de trabalho: contribuição da ergonomia da atividade. Ciência \& Saúde Coletiva, Rio de Janeiro, v. 10, n. 17, p. 2817-2830, 2012.

VOLKOFF, S. As pesquisas francesas sobre as condições de trabalho e sobre a organização do trabalho: dos métodos aos resultados. Revista Brasileira de Saúde Ocupacional, São Paulo, v. 19, n. 74, p. 80-98, 1991.

\section{Contribuição dos autores}

Ambas as autoras contribuíram para a redação do artigo.

Recebido: 17/07/2018

Aprovado: 05/12/2018 